\title{
Analogical Arguments in Persuasive and Deliberative Contexts
}

\author{
Douglas Walton
}

Centre for Research in Reasoning, Argumentation, and Rhetoric

University of Windsor

Windsor, $O N$

dwalton@uwindsor.ca

\section{Curtis Hyra}

\author{
Argumentation Studies \\ University of Windsor \\ Windsor, ON \\ hyra2@uwindsor.ca
}

\begin{abstract}
This paper uses argumentation tools such as argument diagrams and argumentation schemes to analyze three examples of argument from analogy and argues that to evaluate these arguments adequately, it is necessary to take the context of use into account. The evidence drawn from the examples suggests that studying argument from analogy only by identifying the logical form of the argument (for example by building an argument diagram containing the premises and conclusion) is not adequate. To get further, we argue, the argument analyst needs to take into account how a particular argument was used in context to support a conversational goal.
\end{abstract}

Résumé: Cet article utilise des outils d'argumentation tels que des diagrammes d'argument et des schèmes d'argumentation pour analyser trois exemples d'argument par analogie, et soutient que pour évaluer ces arguments de manière adéquate, il est nécessaire de tenir compte du contexte d'utilisation de l'argument. Ces exemples suggèrent que l'étude des arguments par analogie à partir de seulement l'identification de leur forme logique (par exemple en construisant un diagramme des prémisses et de leur conclusion) n'est pas adéquate. Pour aller plus loin, on avance que l'analyste d'argument doit prendre en compte comment un argument particulier a été utilisé dans un contexte pour soutenir un but conversationnel.

Keywords: analogy; analogical arguments; argumentation schemes; context; dialogue types 


\section{Introduction}

By focusing on the logical relations between premises and conclusions on the intended use of specific analogical arguments, this paper argues that the context relating to dialogue type is another important factor to consider when evaluating analogical arguments. The context in which an argument occurs will change how the argument is evaluated. Two types of dialogues identified in Walton (2013) that we will compare and contrast in reconstructing and evaluating analogical arguments are persuasion dialogue, where the goal of each party is to persuade the other to accept his/her thesis, and deliberation dialogue, where the goal is to make a decision about the best course of action to take in a given situation requiring choice. We will show that this is an important distinction to keep in mind when reconstructing and evaluating arguments from analogy. Given the rhetorical force of analogical arguments (Waller, 2001; Guarini, 2004; Bartha, 2009; Bermejo-Luque; 2012), this distinction is important in the pedagogy of analogical arguments, as the undiscerning student might misevaluate the argument, or worse, a strong analogy in a persuasion dialogue might lead someone to take action for the wrong reasons even though the argument was not put forward in a deliberation dialogue.

This paper will proceed in Section 2 by giving a survey of those aspects of the extensive literature on argumentation and analogy that are relevant to the concerns of the paper, and by outlining what we take to be the most important distinctions in this literature pertaining to analogical arguments. ${ }^{1}$ In Section 3 we present and analyze three examples of arguments from analogy found in natural language texts, each of which has its own special lessons for the study of how to evaluate arguments from analogy. The role of common knowledge for filling in implicit premises and for using scripts is brought out. Section 4 provides six conclusions that will

\footnotetext{
${ }^{1}$ As seen in Guarini et. al. (2009), there is an abundance of literature on analogical arguments spanning many fields and disciplines. This paper will deal primarily with research found in argumentation theory, and the distinctions made there.
} 
be extracted from the extensive analyses of the texts of the three examples. The first is that we can identify arguments from analogy only by using several argumentation schemes closely related to arguments from analogy in the three examples. The second is that we need argument diagramming tools to analyze the argument to see how it is supported or attacked by other arguments that occur in the texts. The third is that it is necessary to expand the argument as given in the text further beyond the limits of argument diagram technology in order to take aspects of the context into account. The fourth is that implicit premises and conclusions need to be drawn from common knowledge to expand the argument diagram and to get the argumentation scheme for argument from analogy properly to apply to the given text. The fifth is that it is necessary to take standards of proof into account that can vary among different types of dialogue representing the context of use of the given argument. The sixth is that the textual and contextual evidence that can be extracted from the given text of the case needs to be applied to determine whether the analogy is being used to support an argument or an explanation, or some combination of these, such as in cases of inference to the best explanation.

\section{Survey of the relevant literature}

In this section we review the relevant literature on analogical arguments, and the factors that underlie their formulation and evaluation. One of the preliminary distinctions we establish is between a mere similarity and an analogical argument. Next, we review the literature to highlight a movement from formal considerations to use-based considerations to establish a scheme and evaluate analogical arguments. Our contribution to this literature is the addition of dialogue type as a factor relating to the use of an analogical argument to consider in evaluation. As we will see by way of exam-

ple in the next section, the dialogue type is of practical importance in evaluation because the implications of reconstructions change depending on the dialogue type that is attributed to the context which an analogical argument is put forward. 


\subsection{Mere similarity vs. analogical arguments}

Historically speaking, analogical arguments were not always considered arguments (Govier 1999, p. 138). This is because there was no obvious way to reconstruct analogies in a deductive form, so logicians concluded that analogies deal with similarity, but are not arguments themselves. An analogy that merely establishes a similarity is not an argument. Some theorists have classified an analogy that establishes a mere similarity a "figurative analogy" (Waller 2001, p. 200). ${ }^{2}$ As Bermejo-Luque points out, there must be analogies that are not arguments, as some analogies merely establish a relationship between two things. Inappropriately characterizing mere similarities as arguments that can only be reconstructed as arguments that commit the logical fallacy of begging the question is an error (Bermejo-Luque 2012, p. 6). So, the first important distinction to make is between "mere similarity" and "argumentative analogies".

However, the distinction between so-called "figurative analogies" and analogies which could easily appear to be not arguments may not be as clear-cut as it seems. This short survey of the literature suggests that there is little consensus about what these terms should refer to. Garssen (2009) argues that what are usually called figurative analogies are not analogies at all but are merely presentational devices for argumentation schemes. According to Juthe (2005), some analogies classified as figurative analogies are used in arguments while others are not. Kienpointner (2012) proposes that figurative analogies combine with other types of analogies. One is what Govier calls "a priori analogies", while the other is what Doury (2009) has labeled as "different domain analogies". With regard to these distinctions, a question arises: what is the difference between an argument by analogy which compares objects of distant domains and a figurative analogy?

\footnotetext{
${ }^{2}$ The language of "figurative" comes from Waller (2001), but, the need for a distinction between mere similarity and analogical argument is found in most of the literature (cf. Govier (1999), Guarini (2004), Walton, Reed, Macagno (2008), Bermejo-Luque (2012)).
} 
The issue could also be raised here of whether there could be a specific category called argument from metaphor. Some authors claim that metaphors are really analogies between distant domains (Bowdle and Gentner, 2005). Santibanez (2010) draws a distinction between argument from analogy and something else he calls argument by metaphor. This distinction appears to coincide with the distinction he has also drawn between same domain (literal) analogies and different domain (figurative) analogies.

Trying to get some perspective on this cluster of distinctions, and how it relates to the concerns of this paper, one might also suggest that arguments classified under the headings of "arguments of figurative analogy", "arguments from metaphor", and "arguments from parable" could be put together as a cluster of types that cut across the typologies outlined above. On this approach, some can be classified as different domain analogies, while others could be classified as presentational devices for other types of schemes ${ }^{3}$. We hope in a future paper to address these issues.

\subsection{Induction, deduction, a priori}

One of the central debates over analogical arguments in argumentation theory has centered around the logical structure of analogical arguments. One of the most important treatments of analogy in this regard is Trudy Govier's book The Philosophy of Argument where she provides a thorough account of the differences between inductive, and a priori analogical arguments. An inductive analogy is an analogy that attributes the features offered for comparison by way of empirical observation, or equivalent (Govier 1999, p. 138). Govier resists a conception of induction that is merely "not deductive", a catch-all category for all arguments that do not fit the criteria for being characterized as deductive. There is a difference for Govier between inductive and deductive, and, furthermore, deductive and a priori. Analogies do not fit the criteria to be classified as deductive, as there is not the proper explicit relation between premises and conclusion (Govier 2002). But, there is an im-

\footnotetext{
${ }^{3} \mathrm{All}$ of these different perspectives and distinctions are relevant to the concerns
} 
portant difference between deductive and a priori, such that we should call certain analogies a priori. An a priori analogy is one where the case to which an analogue is drawn is hypothetical or fictional. Whereas an inductive analogy appeals to a similarity between two observable cases, in an a priori analogy, one or both terms need not have a similar connection to reality. For instance, in Jarvis Thomson's violinist analogy ${ }^{4}$, there is no truth or reality to the thought experiment itself. However, the thought experiment is conceived to draw out a certain relation between the case of the violinist and the morality of terminating a pregnancy that resulted from rape. An inductive analogy compares two things in the world, an a priori analogy makes a comparison between a real word case and a hypothetical case to reveal an underlying principle (Govier, 1999, p. 138-140).

Waller disputed the distinction made by Govier. According to Waller, a priori analogies are in fact deductive because when the underlying principle is added to the argument scheme for analogy, the relationship between the premises and conclusion reveals itself to be deductive. Waller essentially re-frames the question in a way that permits the implicit principle to be explicit in the reconstruction and evaluation (Waller 2001, p. 201). This point has been refuted by Govier. In response, Govier pointed out, firstly, that if the principle were obvious or implicit in the analogy itself, then the analogy would not be necessary. If the audience already accepted

\footnotetext{
${ }^{4}$ Thomson's violinist argument is as follows: One morning you wake up to find that, in your sleep, you have been hooked up to a famous violinist. You are hooked up such that your kidneys are filtering her blood. You can have surgery to detach yourself from the violinist, but the surgery will take nine months. Conversely, you can detach yourself right away, but in doing so the violinist will die. This analogy is used to defend terminating a pregnancy that is the result of a rape, because, if you agree that you have no moral obligation to stay attached to the violinist, then, analogously, you have no moral obligation to carry a baby to term (Thomson 1971). What is analogous here is the principle that underlies the example. If you accept the principle in the violinist case, the same principle is operating in the case of abortion. This example is also used to show the difference between inductive, deductive, and a priori analogies, as the violinist case is a thought experiment with no empirical ground.
} 
the principle that underlies the case of the morality of terminating a pregnancy that is the result of rape, then the analogy does not do any work to convince the audience. Secondly, that the underlying principle is the feature of the analogy that makes it an argument, rather than a mere similarity. If the underlying principle is implicit in the way that Waller claims, then the analogy is not deductive, but a mere similarity since the only work that the analogy is doing is to show that there is a similarity (Govier 2002, p. 155-157). ${ }^{5}$

Guarini (2004) accepted Govier's distinction between deductive and a priori analogical arguments. Guarini also makes his own distinction, but this time along the lines of the goal of an analogical argument, what an analogy is used for. Guarini suggests that the differences between Waller's account of deductive analogy and Govier's a priori analogy are weakened when we consider the purpose of the analogy. Guarini offers that classificatory is a more appropriate because "the point of these analogies appears to be to suggest that two (or more) cases be classified or treated in the same way" (Guarini 2004, p. 166). Inductive analogies, then, might be termed predictive as these analogies serve the purpose of making a prediction. ${ }^{6}$ Guarini notes that this classification is not exhaustive but that dividing analogical arguments along these lines in terms of use helps to understand the relevant similarities and differences in the debate (Guarini 2004).

Juthe (2005) drew a similar distinction. Instead of "classificatory", he used "proportional". A proportional analogy in Juthe's sense is one where the relations between two cases are analogous. A predictive analogy for Juthe is one where the properties between two cases are analogous. However, merely having

\footnotetext{
${ }^{5}$ Guarini defends these lines of reasoning in more depth in his paper, "A defence of Non-deductive Reconstructions of Analogical Arguments". In this paper Guarini not only defends the non-deductive approach but offers a new schema that accounts for the strength of an analogy, a point that Walton, Reed, Macagno (2008) include in their schematization of analogical arguments.
} 
similar properties, for Juthe, does not constitute an argument. For a predictive analogy to be argumentative, it must go beyond mere similarity. There must be a new predicate that is assigned in the case of a predictive analogy that was not present in the comparison between similar properties (Juthe 2005, p. 8). There must also be a similarity in the functional role between the two analogues. What is of note here, though, is that both Juthe and Guarini make a distinction between types of analogies in terms of use.

\subsection{Justification vs. Persuasion}

Now that we have seen one reformulation of analogical arguments in terms of the use of the analogy, we turn to another. In a 2012 paper titled "A Unitary Schema for Arguments by Analogy", Lilian Bermejo-Luque draws a distinction between justification and persuasion by appealing to the intended use of an analogy. According to Bermejo-Luque, this is a conceptual distinction that emerges when we analyze the use of an analogy. What is important about the use is that is matters for evaluation. In an analogy used for justification, we employ the analogy as a means of inviting the audience to see a situation as we do. It is a means of providing reasons for a claim that draws on epistemic properties of the analogy. On the other hand, an analogy is used for persuasion when "we put at work its rhetorical properties as a means to induce beliefs and attitudes" (Bermejo-Luque 2012, p. 9). It is important to note that a single analogy might employ both justificatory and persuasive features in its appeal (Bermejo-Luque 2012, p. 8-10).

The difference between the two concepts constitutes the difference between a good analogy and an effective analogy. So, an analogy may be logically fallacious, but still effective, if the audience accepts the claim being put forward on the basis of a faulty analogy. This treatment considers the context of the analogy by appealing again to the difference between figurative (or, in this case explanatory) and argumentative analogies. Insofar as an analogy can make certain features more vivid, an explanatory analogy can be persuasive (Bermejo-Luque 2012, p. 7). 
In the distinction above, persuasion captures the rhetorical goal of trying to win over your audience, to have them accept a claim, "to induce beliefs and attitudes" (Bermejo-Luque, p. 9). In this case, any analogy that is made as an argument is for a persuasive purpose. This is contrasted with justification or explanation, similar to the original distinction made between figurative and argumentative forms of analogy. However, the intended use of the analogy is the distinguishing factor for Bermejo-Luque, rather than the form alone.

\subsection{Persuasion dialogue and deliberative dialogue}

Waller (2001) launched a greater dialogue in argumentation theory that began with Trudy Govier's distinction between inductive and $a$ priori analogies (Govier 1999). Waller's claim here introduces his refutation of Govier's claim that analogies are not deductively valid forms of argument: "Evaluating one type of analogy by the standards for another makes legitimate analogies seem fundamentally flawed" (Waller 2001, p. 199).

What is relevant to the discussion in this paper is the thesis that differing categories of argument use demand different standards of evaluation. In this literature, a distinction is made between an inductive form of analogical argument and other forms of analogical argument. A review of the literature in argumentation theory shows various scholars arguing for a wide range of differentiating factors when it comes to analogical arguments. Another such distinction comes from Marcello Guarini, where he distinguishes between predictive and classificatory analogies (Guarini 2004). The distinction here is made by analyzing the intended use of the analogy. Predictive analogies are used for making predictions, while classificatory analogies are used to classify. Bermejo-Luque follows this lead to make a distinction between analogical arguments used for justification versus analogical arguments used for persuasion (Bermejo-Luque 2012). ${ }^{7}$

\footnotetext{
${ }^{7}$ It is important to note that there are also several approaches to the schematization of arguments from analogy. Most argumentation theories include some
} 
All the distinctions made above are important to reconstructing and evaluating analogical arguments. While these distinctions are invaluable to the study of analogical argumentation, there is another factor that is important to evaluating analogical arguments.

Along the lines of evaluation in terms of use or goals is dialogue type. Dialogue types are idealized classifications of situations in which the interlocutors try to accomplish specific goals. Like the justificatory and persuasive uses, dialogue types may overlap. However, unlike the justificatory and persuasive uses, dialogue types always include argumentation. In this paper, we will show two of the seven dialogue types outlined by Walton (2013) to be relevant to the evaluation of analogical arguments: persuasion dialogue, and deliberative dialogue ${ }^{8}$. Table 2 , on the next page, from (Walton, 2013, p. 9), pinpoints the essential characteristic features of the two types of dialogue as well as the criteria by which the two types are determined.

Insofar as two interlocutors are trying to get the other side to adhere to a standpoint other than the one they are advocating for; persuasion dialogues can be conceptualized in the adversarial para-

treatment and schematization that highlights one aspect or another. The number of schemes and differences between them is a whole other paper (and already has a major contribution by Andre Juthe, (2015)). Some important schemes from the literature include: Govier (1985), Guarini (2004), Juthe (2005), Walton, Reed, and Macagno (2008), Bartha (2009), van Eemeren (2010), Bermejo-Luque (2012).

${ }^{8}$ There are seven dialogue types as outlined by Walton. We follow Walton in his 1992 paper, "Types of Dialogue, Dialectical Shifts, and Fallacies", on the point that dialogue types rarely occur clearly and distinctly from each other, so, the dialogue types are an ideal model to deal with argumentation in natural language where several dialogue types can be mixed together, or where one may be embedded in another (1992, p. 138). We focus on persuasion vs. deliberation to show, by way of comparison, how dialectical shifts change the evaluation of analogical arguments. It is not our goal to analyze all dialogue types, and the evaluation of dialectical shifts between them in the case of analogy, as this would be another paper entirely. The groundwork for a paper that distinguishes between all types is established in this current paper, by distinguishing between two: persuasion and deliberation.

(c) Douglas Walton, Curtis Hyra. Informal Logic, Vol. 38, No. 2 (2018), pp. 213-261. 
digm $^{9}$. This dialogue type will be most familiar to pragmadialecticians as it constitutes the dominant argumentation paradigm that the theory uses, that is, critical discussion. Persuasion dialogue and critical discussion share the goal of resolving a difference of opinion using rational argumentation. While there are rules to a critical discussion, it is not a formal model. So, a persuasion dialogue is classified in terms of a goal that the dialogue type is aimed towards (Walton 2010), along with other characteristics.

\begin{tabular}{|l|l|l|l|}
\hline $\begin{array}{l}\text { Type of } \\
\text { Dialogue }\end{array}$ & $\begin{array}{l}\text { Initial } \\
\text { Situation }\end{array}$ & $\begin{array}{l}\text { Participant's } \\
\text { Goal }\end{array}$ & $\begin{array}{l}\text { Goal of } \\
\text { Dialogue }\end{array}$ \\
\hline Persuasion & $\begin{array}{l}\text { Conflict of } \\
\text { opinion }\end{array}$ & $\begin{array}{l}\text { Persuade other } \\
\text { party }\end{array}$ & $\begin{array}{l}\text { Resolve or clari- } \\
\text { fy issue }\end{array}$ \\
\hline Deliberation & $\begin{array}{l}\text { Dilemma or } \\
\text { practical choice }\end{array}$ & $\begin{array}{l}\text { Co-ordinate } \\
\text { goals and actions }\end{array}$ & $\begin{array}{l}\text { Decide best } \\
\text { available course } \\
\text { of action }\end{array}$ \\
\hline
\end{tabular}

Table 2: Characteristics of persuasion and deliberation dialogue.

Another characteristic that is an indicator of a dialogue type can be found in a deliberation dialogue. Rather than being an adversarial dialogue, deliberation dialogues are collaborative. While the parties of a deliberation may hold differing opinions about how to act in a given situation, ultimately, all of the parties want to make a choice that is beneficial for a group, taking as many interests as possible into account. That the result of a deliberation is optimal for a group is a key distinguishing factor of this dialogue type. The other two key characteristics that distinguish this type from persuasion is the coordinative nature of the dialogue, and that the dialogue is in the service of some action, rather than a belief state (Walton 2013). It is easy to see how the two dialogue types can be confused because there can be instances of persuasion over action,

\footnotetext{
${ }^{9}$ Persuasion dialogue is more adversarial than deliberation, because the two participants compete with each other to prove or disprove a proposition at issue in the persuasion dialogue (in the simplest type of case). In a deliberation dialogue there is no burden of proof (Walton, Toniolo and Norman 2016).
} 
where the speaker is trying to get the hearer to take (or not to take) some course of action (Atkinson et al., p. 2013).

Atkinson et al. (2013) confronted the problem that there is no firm basis in the current argumentation literature for distinguishing in examples of natural language argumentation between those that should be classified as persuasion dialogue and those that should be classified as deliberation dialogue. To highlight the point, they cited the topics of some recent debate digest articles on Debatepedia, such as: "Should there be a ban on sales of violent video games to minors?" and "Should colleges ban fraternities?" (Atkinson et al., 2013 , p. 106). In cases such as these, the topic of the debate concerns a decision to take action and therefore suggests that the debate should be structured in the format of a deliberation dialogue. However, what needs to be observed in such cases is that the debaters arguing about the issue are not in a position to make the decision on whether the course of action at issue should be taken or not. For example, the debaters on the issue of whether colleges should ban fraternities are not actually in a position to either ban them or not. Examined more carefully, such debates should be classified as persuasion dialogues over action (Atkinson et al., $2103,106)$. This observation suggests that distinguishing between cases of persuasion dialogue and deliberation dialogue cannot simply be made by ruling that persuasion dialogue is epistemic ${ }^{10}$ whereas deliberation dialogue is pragmatic ${ }^{11}$. If we can have persuasion over action, then this attractively simple way of distinguishing in practice between persuasion dialogue and deliberation dialogue will not work.

The situation is made more complex by the observation that in many instances of real argumentation in natural language texts there is an embedding of the one type of dialogue into the other (Walton and Krabbe 1995). This phenomenon is illustrated by At-

\footnotetext{
${ }^{10}$ Meaning that it is about the truth or falsity of a proposition representing a claim at issue

${ }^{11}$ Meaning that it is about actions, and more specifically is about whether a particular course of action should be undertaken or not in a given set of circumstances
}

(c) Douglas Walton, Curtis Hyra. Informal Logic, Vol. 38, No. 2 (2018), pp. 213-261. 
kinson et al. (2013, p. 108-114) by the analysis of a running example of a group of academics attending a conference in a strange city after the conference is finished for the day, and they need to find a place where they can have dinner. The argumentation looks initially to be that of a typical deliberation dialogue; the group needs to arrive at a collective decision on which restaurant, of several likely candidates available, is the one that they can agree on as a suitable place to have dinner. But as the dialogue proceeds, at different points, there is a shift to persuasion dialogue. For example, one participant proposes going to a particular restaurant. A proposal for action is a typical speech act characteristic of deliberation dialogue, so at this point, the dialogue seems to be that of a deliberation. But then another participant argues that this restaurant is popular with students, so it must be a good one. Still another participant disagrees, arguing that it might not be a very good restaurant because students tend to go for low-budget fast food. During this subsequence of the dialogue, it has shifted to a persuasion dialogue on the issue of whether a particular restaurant might not be good for the reason cited.

Atkinson et al. (2013, p. 115) go on to draw four points of contrast between persuasion and deliberation dialogues but also go even further to argue that these criteria need to be supplemented by pre-and post-conditions for the speech acts used in the two types of dialogue. This is carried out using formal models of each of the two types of dialogue, and then, in turn, using the speech acts representing the moves as the basis for studying shifts and embeddings between them. One of the most important speech acts is that of the "why-question" which expresses a demand for proof (or supporting argument) of a claim (assertion).

Deliberation dialogue is importantly different from persuasion dialogue in that there is always a burden of proof in a persuasion dialogue, sometimes called a burden of persuasion, set at the opening stage that shifts back and forth from one side to the other during the argumentation stage. Burden of proof is a very important device for helping to decide the outcome of persuasion dialogue. However, in deliberation dialogue, there is no burden of proof set 
at the opening stage determining which side is the winner and which side is the loser at the closing stage (Walton, Toniolo and Norman, 2016). Hence the evaluation of arguments such as argument from analogy needs to be carried out in a different way in deliberation dialogue than the usual way we are familiar with in persuasion dialogue ${ }^{12}$. The basic reason is that persuasion dialogue is all about resolving a conflict of opinions set at the opening stage when the one side puts forward a sequence of argumentation that proves its ultimate conclusion, thereby removing the doubts expressed by the other side. On this model, persuasion dialogue is a fairly adversarial kind of dialogue where the thesis of the one party is opposed to the thesis of the other party, posing a conflict that needs to be resolved (Walton and Krabbe 1995). In contrast, deliberation is better seen as a more collaborative type of dialogue in which the participants will often need to make concessions to the other side to arrive at a decision that is the best choice for the group as a whole (Atkinson et al., 2013).

When viewed in the context of a deliberation dialogue, the argumentation needed to move the procedure forward is not as confrontational as it is in the persuasion type of dialogue. Compromise tends to be more to the forefront and explaining one's point of view in a way that others in the deliberation can appreciate and understand is often more important.

Confusing the two types of dialogue can be detrimental when it comes to arguments, such as arguments from analogy, which occur where it may be unclear to an argument analyst with the proper context of the dialogue should be taken to be. So, we see that it is important to note that there are conceptual differences between the two types of dialogue that play a role in evaluating analogical arguments put forward in each type. That is, the goal of a persuasion dialogue is epistemic, to give reasons supporting the truth or falsity of a proposition, whereas the goal of deliberation is to give reasons

\footnotetext{
${ }^{12}$ For a full treatment of dialogue types and what characterizes each type see (Walton 2013).
} 
for and against an action being considered where a decision needs to be made on what to do (Atkinson et al. 2013).

The differences here reflect, in important ways, the distinction made between justificatory and persuasive uses of analogical arguments. For instance, an analogy used for a justification of a claim deals with the epistemic features of the analogues. However, where a justificatory use of analogy may not constitute an analogical argument, a justificatory analogy used in a persuasion dialogue would constitute an analogical argument. Put in terms of BermejoLuque's distinction, an analogical argument put forward in a persuasion dialogue assumes both justificatory and persuasive features. Where Bermejo-Luque's account differs from an account that considers dialogue type is the goal of the dialogue. Since a persuasion dialogue resolves a difference of opinion, it deals with the epistemic state of the interlocutors. Persuasion dialogues seek to persuade that $x$ is true or false. Deliberation dialogue, on the other hand, has to do with action. So, an analogy made in a deliberation dialogue is not concerned about epistemic features of the dialogue per se, but the effectiveness of the analogy in bringing about group action. For the purposes of evaluating an analogical argument, it is important to keep in mind lest a person confuses the two and acts on a conclusion that was made to be a matter of fact.

The worry here is not that the evaluator derives a normative statement from a descriptive argument. Doing so is only a problem epistemically, not a problem of practice. What is at issue here is that a person mistakes an argument for consideration in the context of accepting an epistemic claim for a context for action (and vice versa). So, the person inappropriately acts on the basis of a claim made in the context of persuasion. This is an important consideration when critically evaluating analogical arguments given the rhetorical strength that analogical arguments sometimes have.

One common factor that underlies these distinctions is the important role that each play in reconstructing and evaluating analogical arguments. Without these distinctions, we might inappropriately judge one type based on the criteria appropriate to another type. In terms of form this means mistaking a comparison for an argu- 
ment, or judging an argument based on deductive validity when it is not in fact deductive, but inductive or a priori. In terms of use, this means evaluating a prediction in terms of a classification or judging an analogy to be good when it is effective.

\subsection{Two schemes}

In the distinctions that have been made so far, each philosopher has offered a new scheme to accommodate the nuances of analogical argument. Since this paper will argue that dialogue type is another consideration in analogical argument evaluation, we will not be contrasting and comparing the schemes. We will note here what might be considered an implicit recognition of dialogue type in the formulation of analogical argument schemes by Walton, Reed, and Macagno in their book Argumentation Schemes. In this book, they provide a detailed survey of the literature and analysis of the schematization of analogical arguments. Ultimately, the compendium of schemes lists two main variations of analogical arguments: Argument from analogy, and practical reasoning from analogy. The scheme for argument from analogy is as follows:

\begin{tabular}{|l|l|}
\hline SIMILARITY PREMISE & Generally, case C1 is similar to case C2. \\
\hline BASE PREMISE & A is true (false) in case $\mathrm{C} 1$. \\
\hline CONCLUSION: & A is true (false) in case $\mathrm{C} 2$. \\
\hline
\end{tabular}

The scheme for practical reasoning from analogy (Walton, Reed, Macagno 2008, p. 315-316) is as follows. ${ }^{13}$

\begin{tabular}{|l|l|}
\hline SIMILARITY PREMISE & Generally, $\mathrm{S}_{2}$ is similar to $\mathrm{S}_{1}$. \\
\hline BASE PREMISE & $\begin{array}{l}\text { The right thing to do in } \mathrm{S}_{1} \text { was to carry out } \\
\text { action } x .\end{array}$ \\
\hline CONCLUSION & The right thing to do in $\mathrm{S}_{2}$ is carry out $x$. \\
\hline
\end{tabular}

In comparing the two schemes, we find that a use distinction is being made that runs parallel to the distinction between a persuasion

\footnotetext{
${ }^{13}$ We present here the positive scheme. There is also a negative scheme not shown here.
} 
dialogue and a deliberation dialogue. In the scheme for argument from analogy, the analogy put forward establishes the truth or falsity of some claim. This is precisely the goal of a persuasion dialogue, to resolve a difference of opinion. As noted above, a persuasion dialogue deals primarily with belief states or epistemic conditions of acceptance. So, while dialogue types can overlap (as do different use distinctions made above might overlap), the epistemic nature of a persuasion dialogue is mirrored in the epistemic nature of the argument from analogy scheme. Conversely, a deliberation dialogue has the goal of deciding the best course of action. What is at issue here is not an epistemic state, but a practical consideration of how to act. This kind of consideration is mirrored in the scheme for practical reasoning from analogy since this scheme is in consideration of analogy used to argue for one course of action over another. When the dialogue types and schemes are compared with each other, we find that these two schemes are able to accommodate these two dialogue types, and that the very need for a scheme that focuses on epistemic features of arguments vs. a scheme that focuses on practical features reflects the dangers of confusing one of these uses or goals for another.

It seems that we have come full circle. We began with a distinction between figurative and argumentative analogies that relied on the form of the analogy to tell the difference between analogies and analogical arguments. A further investigation of form brought us into the inductive, deductive, a priori debate. From this debate, a distinction between classificatory and predictive analogies prioritized the use of an analogy over its form. Also, we see that the original distinction between figurative and argumentative analogies can also be framed in terms of use as they can form. Finally, use and form can both be reflected in schemes for analogical arguments, as well as dialogue types ${ }^{14}$. Since the evaluation of an analogical ar-

\footnotetext{
${ }^{14}$ We acknowledge here that Andre Juthe (2016) has distinguished between as many as six factors that act on analogical arguments. While we do not necessarily agree with all distinctions made by Juthe, we also do not hold that use and form are the only two distinctions that can be made. This paper focuses on the interaction of dialogue types for reconstruction and evaluation. In particular, this
} 
gument differs in form between two schemes, we have a good basis for considering dialogue type as an important consideration for evaluation of an analogical argument in terms of its use in context. Furthermore, we see that use can be differentiated from form in dialogue types and that the use of analogical argument can change the reconstruction of an analogical argument in argumentation schemes, as we will see by way of example in the net section. These are useful distinctions indeed and show the complication of analyzing analogies in context. The next section will build on this insight by using three arguments from analogy randomly selected from nineteen examples found in Newsweek, 2009-2012, and a legal example.

\section{Three examples}

\subsection{The baseball example}

In this example, the use (and dialogue type) is given by the context of a legal trial. This example is interesting because it shows that the use is not only dictated by the text, but the context itself provides considerations and constraints on dialogue types. In this case, the analogical argument reconstruction is important to how a judge or jury interprets the analogy under consideration and does not move too hastily from an epistemic justification to a practical conclusion.

When Barry Bonds hit his record-breaking 73rd home run in 2001, the ball landed in the webbing of a mitt worn by fan Alex Popov but did not fully go into the mitt. The instant that the ball entered his mitt, Popov was thrown to the ground by a mob of fans, eager to catch it, because it would probably be very valuable. The 70th home run ball hit by Mark McGwire in 1998 had sold for \$3 million. As Popov was buried face down under several layers of people, Patrick Hayashi, another fan standing nearby, picked up the loose ball, put it in his pocket and as someone pointed a video

paper shows the importance of taking these two types into consideration. Since argument schemes are forms of argument, and dialogue types deal primarily with the use of arguments, we deal primarily with these considerations.

(c) Douglas Walton, Curtis Hyra. Informal Logic, Vol. 38, No. 2 (2018), pp. 213-261. 
camera at Hayashi he held the ball in the air. Popov subsequently sued Hayashi claiming that he and not Hayashi had the right to ownership of the ball. (Popov v. Hayashi 2002 WL 31833731 (Cal. Superior, Dec. 18, 2002)).

The rule used to establish ownership in the case of Popov $\mathrm{v}$ Hayashi was that in order to claim possession of the ball, and therefore have a right to ownership of it, the agent must have control of the ball, and must retain control even if interrupted by the actions of others. But the court also ruled that if an agent takes steps to achieve possession of something, but is interrupted by the actions of others, he can be said to have a pre-possessory interest in the property. On this basis, the judge split the value of the ball between Popov and Hayashi for the reason that the award to one party would be unfair to the other. The legal arguments, in this case, were thought to be so interesting from the point of view of studying argumentation that a special issue of the journal Artificial Intelligence and Law (volume 20, no, 1, 2012) was devoted to analyzing it.

During the argumentation that took place in the court, law professors who were consulted cited several precedent cases about hunting and capturing animals taken to be analogous to the current case. In the case of Pierson v. Post, Pierson was chasing a fox with hounds when Post caught the fox. The court decided in favor of Post on the basis that mere pursuit did not give Pierson the right to claim the fox as his property. In another case, Young v. Hitchens, Young had spread his net and almost closed it when Hitchens went through an opening in the net with his own net and used his net to catch the fish. The court attributed ownership to Hitchens. In still another case, one man harpooned a whale, and after it was washed ashore, it was found by another man who sold it to a third man. The court ruled for the harpooner, on the basis that the man who found the whale should have reported it and collected a fee.

The curious thing about the baseball case is that there are three arguments from analogy in it, deriving from the three precedent cases, the fox case, the fish case, and whale case, each of which, as argued by the experts in the trial, is similar to the baseball case. So, 
here we have three arguments from analogy. All three of these arguments from analogy are relevant, but none of them was decisive in resolving the issue to be disputed in the trial, the disputed question of which side had the right to ownership of the baseball.

To get some idea of how the three arguments from analogy are combined within the argumentation in the trial, Figure 1 displays each of these three arguments as linked arguments in relation to the claim on the one side of the trial. The issue of the trial was whether the court should decide in favor of the retriever of the baseball, Hayashi, or the pursuer of the baseball, Popov, who ultimately did not retrieve it, in the sense of having actual possession at the end of the sequence of events. The ultimate issue of the trial was the question of which party, the pursuer or the retriever, on the basis of the evidence admitted, should legally be judged to be the owner of the ball. It is impossible to represent the entire sequence of argumentation as it relates to the ultimate issue of the trial in an argument diagram of the conventional sort. However, this is done in Figure 1, by looking at part of the argument from the point of view of one side.

The conclusion of the sequence of argument, shown at the left in Figure 1, is the statement that the court should decide for the retriever in the baseball case, Hayashi. And as shown, there are three arguments from analogy relevant to supporting or attacking this conclusion. The arguments a1 and a 2 support the conclusion, while the argument a3 attacks the conclusion. Hence the two arguments from analogy at the top are shown as pro arguments with respect to the conclusion, while the argument at the bottom is shown as a con argument, attacking the ultimate conclusion. 


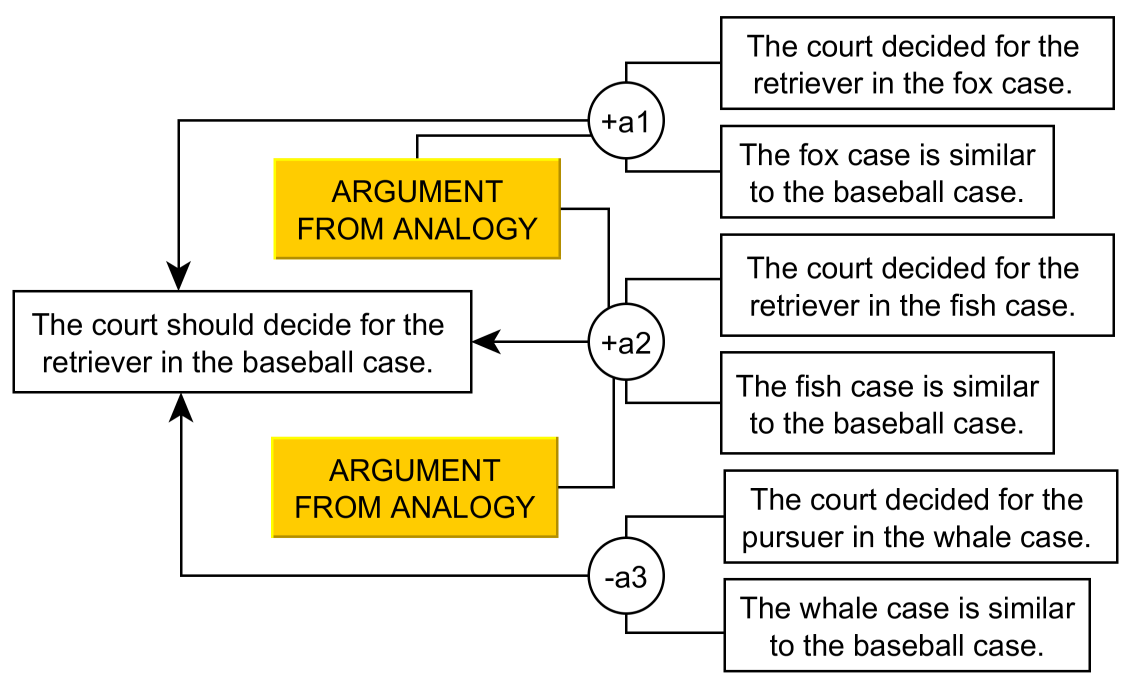

Figure 1: Arguments from Analogy in the Baseball Example

What examination of this case has brought out is that in no instance is argument from analogy a conclusive argument, either supporting or refuting the conclusion in the case. Instead, it is best modeled as a defeasible argument, as represented by the argumentation scheme for argument from analogy. To say that it is a defeasible argument means that it is not decisive by itself to prove the conclusion at issue in the given case beyond all doubt. It should be seen as open to counterarguments that might defeat it, as new evidence enters into the case. What has been shown here is that an argument from analogy, to be properly understood and analyzed, has to be seen in a context of a dialogue, in this case of a legal dispute between two parties about which side should have ownership rights to the baseball. The judge's ruling took these arguments from analogy into account but ultimately decided the issue on the basis of a completely different type of argument, namely argument from fairness, which has its own argumentation scheme (Walton 2014). What this shows is that context is important and that arguments from analogy are inherently defeasible and need to be judged in light of the ultimate issue to be disputed in a case. 
Furthermore, the interplay between the context of a legal trial and the arguments put forward provides an interesting example of embedded dialogue. Legal trials fit the ideal model of persuasion dialogues: they are adversarial, involve a burden of proof, and are put forward to alter the epistemic state (from neutral) of the judge or jury. It is important to note here that the deliberation of the jury in civil proceedings ("we should find in favor of the plaintiff/defendant") is distinct from the arguments given by lawyers for the consideration of the jury. The jury deliberations are deliberation dialogues, collaborative (though, often rhetorically adversarial) efforts to come to the best course of action. This distinction is made clear by considering the role of the parties involved. Each lawyer is engaged in a persuasion dialogue with the judge/jury. They are not collaborators since each lawyer is interested in winning the case for him or herself. They may use collaborative language ("We just want to see the best outcome for our client and receive a just decision so that no one else in this situation has to suffer through this again"). However, these parties are not collaborators since the judge/jury is meant to maintain a position of neutrality until the trial has ended, at which point, presumably, they have the information needed to make a decision. Since there are two parties trying to convince the judge of opposite conclusions (defendant is guilty/defendant is not guilty), a trial cannot be considered a deliberation.

In fact, this is precisely why the consideration of dialogue type is important in a legal trial. As we see in the argument diagram in figure 1, multiple arguments from analogy are made that lead to the finding. However, each case is a persuasion dialogue, where the lawyer is arguing to a neutral party regarding the truth/falsity of a claim. The judge or jury either accepts or rejects the truth or falsity and uses that conclusion as a premise in a deliberation. It is thus the use of analogy that determines the evaluation. The evaluation of the analogy does not depend on the structure itself; rather, it is the use in a dialogue type that contributes to the evaluation. In this case, moving too quickly from persuasion to deliberation can be 
problematic in legal proceedings. Let's turn to some reconstructions to see this in practice.

In the baseball example, we have the following reconstruction:

\begin{tabular}{|l|l|}
\hline SIMILARITY PREMISE & $\begin{array}{l}\text { Generally, the fishing case is similar to the base- } \\
\text { ball case. }\end{array}$ \\
\hline BASE PREMISE & $\begin{array}{l}\text { Legal precedent } \mathrm{x} \text { is true (false) in the fishing } \\
\text { case. }\end{array}$ \\
\hline CONCLUSION & $\begin{array}{l}\text { Legal precedent } \mathrm{x} \text { is true (false) in the baseball } \\
\text { case. }\end{array}$ \\
\hline
\end{tabular}

Here we see that the conclusion of the argument is not "therefore we should apply legal precedent $x$ in the baseball case". Given the dialectical nature of legal proceedings, new arguments or evidence that might undermine accepting that the legal precedent/principle acting in the source case should be applied to the target case. The first step in a legal proceeding is establishing the truth/falsity of the claim. Accepting the truth/falsity of the first argument provides a premise in some further deliberation by the judge/jury:

\begin{tabular}{|l|l|}
\hline SIMILARITY PREMISE & $\begin{array}{l}\text { Legal precedent } x \text { applies similarly in the base- } \\
\text { ball case as it does to the fishing case (the con- } \\
\text { clusion of the persuasion dialogue). }\end{array}$ \\
\hline BASE PREMISE & $\begin{array}{l}\text { The right thing to do in the fishing case was to } \\
\text { apply legal principle } x \text { to find in favor of plain- } \\
\text { tiff/defendant. }\end{array}$ \\
\hline CONCLUSION & $\begin{array}{l}\text { The right thing to do in the baseball case is to } \\
\text { apply legal principle } x \text { to find in favor of the } \\
\text { plaintiff/defendant. }\end{array}$ \\
\hline
\end{tabular}

Comparing these two schemes makes it clear that you must first accept the truth or falsity of the analogy in order to move to deliberation regarding the best course of action. Otherwise, we commit an is/ought fallacy. Figure 1 above shows the three arguments from analogy, the first three comparisons (the fox case, the fish case, and the whale case) are all part of the legal proceedings. The deliberation of how to interpret the epistemic claims made in the persua- 
sion dialogue occurs in the second stage, ultimately leading to the conclusion of the appropriate finding in the baseball case. In legal proceedings that rely heavily on analogies, such as this one, the best way to proceed is in slow and careful steps between dialogue types. The consequence of not recognizing the switch in dialogue types, in this case, is seen when we move too hastily between dialogue types. ${ }^{15}$

\subsection{The appeaser example}

The next example illustrates an extensive use of a historical analogy for a purpose that is argumentative. In this example, a Newsweek article entitled Oval Office Appeaser (William Broyles, Newsweek, August 22 and 29th, 2011, p. 28), the author claimed that President Obama "has turned out to be the Neville Chamberlain of American politics, drifting toward national catastrophe, one compromise at a time". We call it the appeaser example. The claim made is very much a partisan one, and so it is clear that the text presented in the article is best interpreted as representing an argument and not an explanation. The article is organized around six basic comparisons between Chamberlain's actions before World War II and what the author describes as Obama's actions leading up to August 2010. Each of these six pairs of actions as described by the author are cited in Table 1 (below), where they are more or less quoted from the original text with some details paraphrased or omitted. The intent is not to quote all the wording exactly, but to summarize each claim using the language of the author.

The main departures from quotations from the text of the article are in comparisons $\mathrm{C} 4$ and $\mathrm{C} 5$, where the sentences shown in square brackets are taken to represent items of common knowledge that many readers of the article would be expected to have from their acquaintance with pre-World War II history. Here, Chamberlain has been presented as the classic case of an appeaser whose diplomatic efforts to prevent war dramatically failed. No politician likes to be compared to Chamberlain, who is called an "appeaser".

${ }^{15}$ For another treatment of analogies in a legal setting see Guarini (2016). 
Therefore, the argument against Obama based on the comparison to Chamberlain is recognizably partisan. Chamberlain is regarded as having emboldened the Nazis, which is taken by the readership of the magazine to be a highly negative consequence. The statement in C6 makes this clear. Chamberlain is praised for doing one bold thing namely having resigned.

\begin{tabular}{|c|c|c|}
\hline & What Chamberlain Did & $\begin{array}{l}\text { Why Obama's Actions are Compa- } \\
\text { rable }\end{array}$ \\
\hline $\mathrm{C} 1$ & $\begin{array}{l}\text { Desperate to keep the peace, } \\
\text { Chamberlain caved into every } \\
\text { German demand. }\end{array}$ & $\begin{array}{l}\text { Like Chamberlain, Obama is a } \\
\text { decent man who values peace and } \\
\text { civility at any cost, but he is no } \\
\text { match for his Republican adver- } \\
\text { saries. }\end{array}$ \\
\hline $\mathrm{C} 2$ & $\begin{array}{l}\text { Chamberlain had a weak hand } \\
\text { and played poorly. }\end{array}$ & $\begin{array}{l}\text { Obama had a strong hand and } \\
\text { threw in his chips. He meekly al- } \\
\text { lowed the } 60 \text {-vote supermajority } \\
\text { needed to shut off a Senate filibus- } \\
\text { ter. }\end{array}$ \\
\hline $\mathrm{C} 3$ & Chamberlain betrayed his allies. & $\begin{array}{l}\text { Obama left democratic values and } \\
\text { programs undefended so that thou- } \\
\text { sands of Democrats from Congress } \\
\text { to city councils went down to de- } \\
\text { feat. }\end{array}$ \\
\hline $\mathrm{C} 4$ & $\begin{array}{l}\text { [Everyone knows that Chamber- } \\
\text { lain came back from Germany } \\
\text { waving a piece of paper purport- } \\
\text { ing to represent a victory.] }\end{array}$ & $\begin{array}{l}\text { After each betrayal, Obama came } \\
\text { out waving a piece of paper repre- } \\
\text { senting a one-sided agreement to } \\
\text { appease the Republicans }\end{array}$ \\
\hline $\mathrm{C} 5$ & $\begin{array}{l}\text { [The Nazis were emboldened by } \\
\text { Chamberlain's appeasement.] }\end{array}$ & $\begin{array}{l}\text { Emboldened by Obama's ap- } \\
\text { peasement, the GOP has set its } \\
\text { sights on dismantling government. }\end{array}$ \\
\hline $\mathrm{C} 6$ & $\begin{array}{l}\text { Chamberlain did one bold thing. } \\
\text { He resigned so Churchill could } \\
\text { take over. }\end{array}$ & $\begin{array}{l}\text { There is one bold thing Obama } \\
\text { could and should do. He should } \\
\text { bow out of the race and throw his } \\
\text { support behind Hillary Clinton. }\end{array}$ \\
\hline
\end{tabular}

Table 1: A list of the six comparisons in the appeaser example

On this interpretation of the text, the ultimate conclusion of the argument is that the right thing for Obama to do is to resign. There- 
fore, it is clear that rational deliberation is involved, and that practical reasoning, goal-directed reasoning to a recommended action, is part of the sequence of argumentation. Once again, to repeat, the highly partisan nature of the article is apparent. But it is a recommendation for action.

The question is raised therefore whether the argumentation in this case constitutes a fallacious argument from a faulty, inappropriate or unjustified analogy, or whether enough evidence from the historical data has been presented to evaluate the argument as carrying some weight, even though as a defeasible argument it is subject to rebuttal. As always in such cases, the burden of proof depends on the standard of proof appropriate for the contextual use of the argument in question. Even though the argument is partisan, making a case for one side while taking into account some objections from the opposed side is a reasonable format for a discussion of the current political situation. On the other hand, Chamberlain has a bad reputation historically as an "appeaser" who took the position that he could make an agreement that would stand up to an aggressive dictator who had proved in the past that he did not live up to his agreements. The upshot is that Obama is made to look extremely bad by comparing him to the classical instance of an appeaser in history, someone whose actions would be almost universally condemned by the Newsweek readers, and subsequent readers of the article for that matter.

To analyze the structure of the argumentation in this example, we begin with a diagram. Figure 2 (below) only shows the part of the argumentation in the example, the part shown in the comparison row $\mathrm{C} 6$ in Table 1. A lengthier analysis is required to show how the prior five comparisons feed into it. The interpretation proposed here is that these five comparisons, as shown in Figure 2, support the statement that the case of Chamberlain is similar to that of Obama. Each of them, by claiming a similarity between the source and the target case, prepares the way for the final comparison of C6 which directly supports the ultimate conclusion. Therefore, when considering the use of the analogical argument, we see that it should be evaluated in the context of a deliberation dialogue, 
yielding a different conclusion than were it evaluated as part of a persuasion dialogue.

Hence there are two ways of interpreting the argument from analogy in the Chamberlain example. The first way is to view each of the five comparisons shown in Figure 2 as a linked argument that supports the similarity premise. According to this way of analyzing the sequence of argumentation, as shown in Figure 3, each of the five comparisons identified in Table 1 is represented by a separate linked argument.

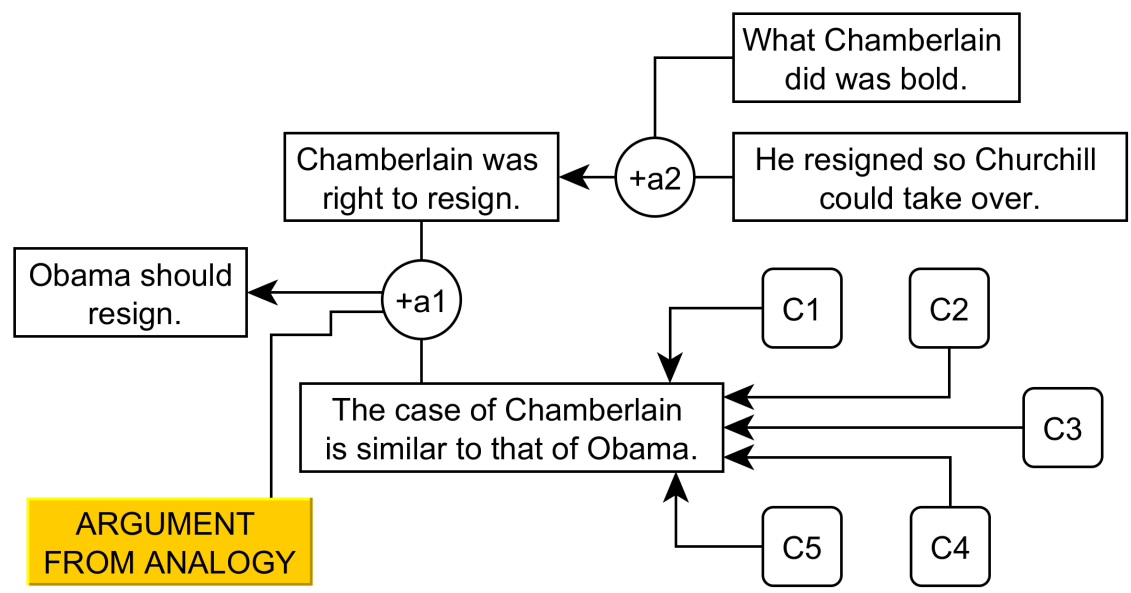

Figure 2: First reconstruction of the appeaser example

The comparison $\mathrm{C} 1$ in Table 1 is represented by argument a1 in Figure 3. What is important to realize is that according to this way of interpreting the argument, each linked argument in the sequence a1,.., a5 is represented as a separate argument, not connected to any of the other arguments in the sequence. According to this way of modeling the argument, each linked argument supporting the similarity premise, which in Figure 3 is shown as the conclusion at the left, the statement that the case of $\mathrm{C}$ is similar to that of $\mathrm{O}$, is an argument in its own right. An asset of this approach is that it enables distinct types of similarity to characterize different kinds of analogical arguments, all based on an underlying abstracted struc- 
ture. For depending on the nature of the abstracted common feature, different rules of inference will apply (Macagno et al. 2016).

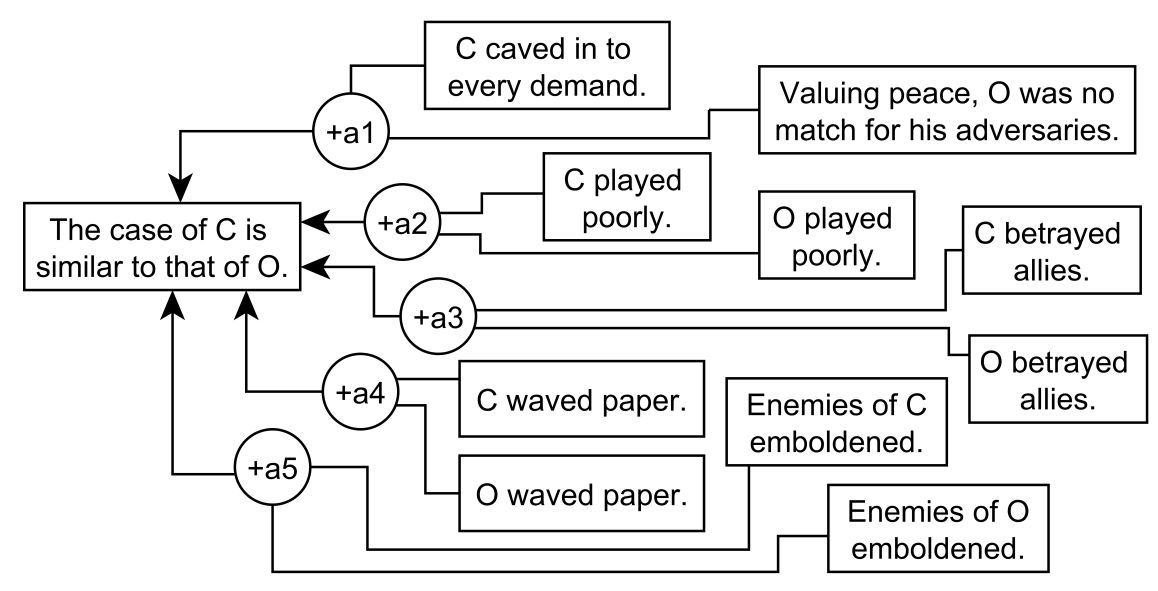

Figure 3: Comparisons in the appeaser example as linked arguments

In this form of argument, the comparison is made between the source case and the target case, and this comparison is used to support the claim that there is a similarity between these two cases. Viewed in this way, the comparisons are used to provide evidential support for the similarity premise of an argument from analogy.

The other way to represent the sequence of argumentation in the Chamberlain example is not to see the comparisons supporting the similarity premise as separate from each other, but as a series of subarguments forming a cumulative chain of argumentation. $\mathrm{Cu}-$ mulative argumentation is a distinctive and reasonable form of argument in its own right in which each step in a sequence of argumentation presents new evidence that makes the previous argument stronger. In cumulative argumentation, one argument provides some typically small support to a hypothesis, but as new arguments are brought forward, support for the claim becomes stronger and stronger at each step (Walton and Gordon 2017). 
In the Study in Scarlet Watson had returned from a military campaign in Afghanistan when he was interviewed by Holmes as a tenant to share Holmes' flat. Holmes asked Watson if had been in Afghanistan. Watson was amazed how Holmes could know this, but Holmes explained his chain of reasoning (quoted from 'A Study in Scarlet', Arthur Conan Doyle, The Complete Sherlock Holmes, vol. 1, Garden City, Doubleday, p. 20-21).

Here is a gentleman of a medical type, but with the air of a military man. Clearly an army doctor, then. He has just come from the tropics, for his face is dark, and that is not the natural tint of his skin, for his wrists are fair. He has undergone hardship and sickness, as his haggard face says clearly. His left arm has been injured. He holds it in a stiff and unnatural manner. Where in the tropics could an English army doctor have seen much hardship and got his arm wounded? Clearly in Afghanistan.

Conan Doyle was a medical doctor, and cumulative argumentation of this sort is common in many instances of medical diagnosis and scientific reasoning to support (or refute) a hypothesis.

The argumentation in the appeaser example works in a comparable way, as shown in Figure 4. As each conclusion in the middle column is supported by a linked argument with two premises, a series of five conclusions is generated, each one stating a similarity in a certain respect. For example, in a1, the two premises support the conclusion that Chamberlain is similar to Obama in a certain respect, listed as $\mathrm{R} 1$, referring to the first respect ( $\mathrm{C} \operatorname{sim} \mathrm{O}$ R1).

On the right, the five arguments a1 to a5 are displayed vertically as linked arguments, each of which has two premises and each of which supports a conclusion stating that an action of Chamberlain is alleged to be similar to an action of Obama in a certain respect R. For example, at the top level the case of Chamberlain is said to be similar to the case of Obama in respect R1. Figure 4 shows how the argument from analogy in the appeaser example can be visualized as the cumulative outcome of a sequence of five comparisons. In the first argument a1 there is an increase in the strength of the argument a6 represented as $\mathrm{x}$. Then at $\mathrm{a} 2, \mathrm{x}$ is increased to 
strength $x+I$, and so forth to a5, where the increase is $x+k$. When all four increases have been added by a5, the final outcome is a strengthened cumulative argument supporting the premise Sim5R of the argument from analogy (a6). It is important to emphasize that we do not have five arguments from analogy, as the appeaser example is represented in Figure 4. We only have one argument from analogy, a6, and five arguments supporting one premise of the argument from analogy.

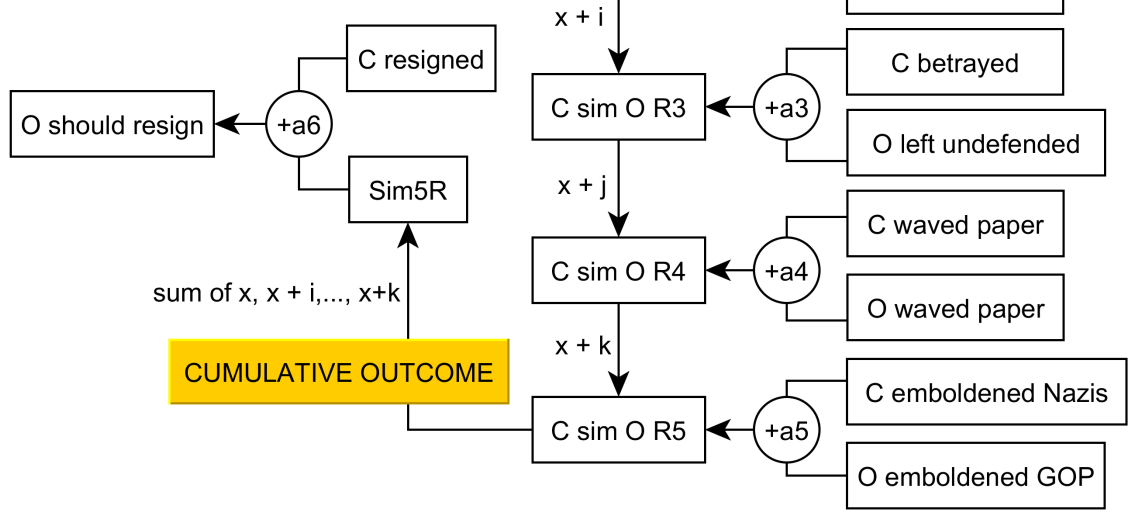

Figure 4: Cumulative buildup of support for an argument from analogy

This way of interpreting the sequence of five comparisons in the appeaser example makes it clear how there is a cumulative buildup of evidence from the first comparison to the next one, through to the final step at the sixth comparison. But is there a cumulative buildup of evidence of this kind in the sequence of comparisons shown in Table 1? Each comparison shows that Obama's actions are similar to the previous actions of Chamberlain in a certain 
respect. And it does move the argumentation forward so that as each similarity between a pair of actions is accepted as holding, there is a gradual buildup of evidence so that the ultimate conclusion that the two cases are similar is more strongly supported at the fifth comparison than it was at the first one. But does the conclusion follow that Obama should resign, as Chamberlain did?

The problem comes in with the final step in the sequence at the conclusion, where it is claimed that Chamberlain was right to resign, and that, by comparison, Obama should also carry out the action of resigning. A lot of evidence would be relevant to fairly evaluating a historical and political argument such as this one. The argument, as presented is highly one-sided and partisan because no dissimilarities between the two cases are even considered that could undermine support by attacking the conclusion directly or by attacking the comparisons that it is based on. Pro and con argumentation is needed to consider both the arguments for and against in such cases. So, we see that this is one side of a deliberation, where the audience is invited to make an inference of their own in regarding then-President Obama.

\subsection{The land mines example}

Whereas the first two examples fit into the category of persuasion dialogue and deliberation dialogue respectively, the third example shows the complexity of argument reconstruction and evaluation when we are dealing with a case of embedded dialogue types.

This example is from Newsweek magazine, May 9, 2011, pages 34 to 37. It is part of an article entitled Saudi's Surprise Renegades. The article described a situation in Saudi Arabia in 2011 in which women demonstrators calling for the release of their imprisoned relatives were making the regime in that country very nervous. The article interviewed Mohammad al Qahatani, the head of the Saudi Civil and Political Rights Association, the closest thing the country has to a civil rights group. The example quoted below appears on page 37. Qahatani advised that any change must be gradual because the public lacks the common ground that would be needed to rapidly change the current situation of civil and political rights. 
The only serious way to seek change is by slow and concentrated steps. Being an activist in Saudi Arabia is like wandering through land mines that can blow up at any second.

The article is attempting to explain to readers of Newsweek who may not be familiar with conditions in Saudi Arabia that speaking out against government policy can be very dangerous. But the article, including the two sentences quoted above, does not consist exclusively of describing the facts and offering explanations of them. The part quoted above can be interpreted as expressing an argument that offers advice and supports it by using an analogy.

Hence the quoted part can reasonably be interpreted as putting forward an argument from analogy, but since explanations are an important part of the article, some attention needs to be paid to the question of whether the quoted part is an explanation or an argument. Arguments from analogy are very common, but analogies are also often used to convey an explanation.

Consider the following example. An exoplanet is a planet that orbits a star other than the sun. Scientists are currently viewing these exoplanets using telescopes, but there is a problem of glare. It is hard to see a planet orbiting a host planet because the host planet throws off so much light, making it exquisitely difficult to photograph the orbiting planet (Portraits of Worlds, The Economist, Nov. 26, 2016, 72). To convey the difficulty, the article uses a common analogy: "photographing an exoplanet is like trying to take a picture, from thousands of kilometers away, of a firefly buzzing around a lighthouse". In this instance, the article is using the analogy of the firefly and the lighthouse to explain the problem of how difficult it is to photograph an exoplanet. It is not using the analogy to argue that it is difficult for scientists to take this kind of picture. The typical reader of the article does not doubt that this task is hard for the scientists, not needing an argument to prove that the task is hard. What the reader needs is an explanation of why this task is so hard. The analogy is used to help the reader understand why the task is difficult. Understanding is conveyed by using a comparison with a task where the problem can be better appreciated by the reader. 
In contrast, in the land mines example, the analogy is used as an argument. In the two statements quoted above Qahatani is giving advice by counseling readers of Newsweek what form of action should be taken, and in particular, arguing that it would not have been prudent to stage public civil rights protests at the time.

Let's begin by identifying the premises and conclusion of the argument. An argument diagram showing what would seem to be the premises and the conclusion can be produced as follows. The conclusion appears to be the initial statement that the only serious way to seek change is by slow concentrated steps. The premise appears to be the second statement, which says that being an activist in Saudi Arabia is like wandering through land mines. But the second statement presents an analogy. So, the problem is to make it part of the argument in such a way that it conforms to the scheme for argument from analogy. The scheme always has a target statement and a source statement. The source statement says that something has a particular property, and the target statement says that something else, something that can be very different in certain respects, also has this property. In this instance, the property is that of seeking changes by slow and concentrated steps. This is said to be the only serious way for an activist to seek change in Saudi Arabia. Why is it said to be the only serious way to proceed? The answer is that it is like wandering through land mines that can blow up any second. The assumption that could be accessed by the reader as a matter of common knowledge is that if you were wandering through land mines that can blow up any second, the only serious way for you to proceed would be by slowing concentrated steps. Why would the reader be willing to accept this assumption based on common knowledge, even if he or she has never been in a situation of wandering through land mines that can blow up any second? Plausibly the answer to this question is that the reader has watched movies or is familiar through exposure to other everyday sources to accounts of soldiers, or even children being killed or injured by accidentally finding themselves in a situation where they are wandering through land mines. It is certainly a picturesque analogy that graphically conveys the idea that for activists to seek 
change in Saudi Arabia without proceeding by slow and concentrated steps is very dangerous.

A way of configuring the structure of the argument based on this interpretation is shown in Figure 5. The scheme for argument from analogy is supposed to fit into node marked $+\mathrm{a} 1$, where the plus sign indicates a pro argument.

The only explicit statements used in the argumentation are the conclusion of argument al and its bottom premise. The implicit premises, derived from the broader context of the article in which this argument from analogy occurs, are marked as rectangles having borders with broken lines. The common knowledge premise supporting the second argument stating that, generally speaking, wandering through minefields is very dangerous, backs up the implicit conditional premise used in the first argument. Much of the substance of the Newsweek article is a description of the dangers of activism in Saudi Arabia by citing a number of examples. In the interpretation given here, this evidence is taken to support the contention that activism in Saudi Arabia is similar to wandering through a mine field.

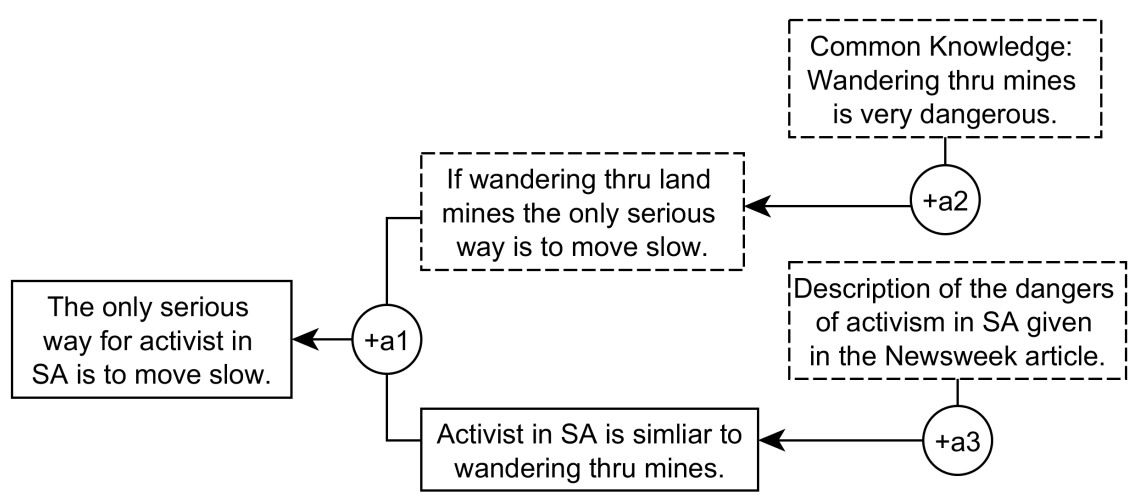

Figure 5: Argument map of the land mines example

An even greater depth of representation of the argument could be offered by showing how it involves the argumentation scheme for argument from negative consequences, of which the type of argu- 
ment called argument from danger is a subspecies (Walton, Reed and Macagno, 2008, 334).

Here we have a situation where we have an analogy that appears to be an argument, and we want to reconstruct it for evaluation. The importance of the interplay between form and use becomes apparent here. As we often try to reconstruct on epistemic grounds, we might first opt for the scheme for analogical argument:

\begin{tabular}{|l|l|}
\hline SIMILARITY PREMISE & $\begin{array}{l}\text { Generally, the danger of walking through land } \\
\text { mines is similar to the danger being an activist in } \\
\text { Saudi Arabia. }\end{array}$ \\
\hline BASE PREMISE & $\begin{array}{l}\text { The necessity of proceeding with caution is true } \\
\text { of walking through land mines. }\end{array}$ \\
\hline CONCLUSION & $\begin{array}{l}\text { The necessity of proceeding with caution is true } \\
\text { of being an activist in Saudi Arabia. }\end{array}$ \\
\hline
\end{tabular}

This reconstruction begins with the assumption that the use or context of the analogy is persuasive, to convince someone of something or another. Since most of the text is in the vein of an explanation, it seems reasonable to assume that this example fits this form. What this does not capture in the implied premises of the dangers of walking through a minefield, and the dangers given in the article regarding activism in Saudi Arabia. Also, we note that the form of the argument suggests some practical use regarding how to proceed in each case. Detecting that the argument might better fit this form, we reconstruct it as follows:

\begin{tabular}{|l|l|}
\hline SIMILARITY PREMISE & $\begin{array}{l}\text { Generally, walking through land mines is similar } \\
\text { to being an activist is Saudi Arabia. }\end{array}$ \\
\hline BASE PREMISE & $\begin{array}{l}\text { The right thing to do when walking through land } \\
\text { mines is to proceed with caution. }\end{array}$ \\
\hline CONCLUSION & $\begin{array}{l}\text { The right thing to do as an activist in Saudi Arabia } \\
\text { is to proceed with caution. }\end{array}$ \\
\hline
\end{tabular}

For the student learning argument reconstruction, the analogy in question seems straightforward from the beginning. There is obviously an analogy involved. From a pedagogical perspective, 
we might grant the beginner either interpretation presented above. However, neither on its own is adequate to the text, and the argumentation theorist needs the consideration of use (therefore dialogue types) to fully explain what is happening in the example. In this case, the argument seems to fit the form for practical reasoning much more closely. We find it somewhat problematic, or at least unsatisfying that a practical argument is being made here. Why would Qahatani be advising the readers of Newsweek on how to be an activist in Saudi Arabia? One consideration with the problems associated in each case is a problem with the separation of theory. Maybe there is no important difference between the forms, such that the scheme for practical reasoning is reduced to the form for analogical argument:

\begin{tabular}{|l|l|}
\hline SIMILARITY PREMISE & Generally, Case 1 is similar to Case 2. \\
\hline BASE PREMISE & "The right thing to do is action $x$ " is true of Case 1 \\
\hline CONCLUSION & "The right thing to do is action $x$ " is true of Case \\
& 2. \\
\hline
\end{tabular}

Reconstructing this reduction for this example:

\begin{tabular}{|l|l|}
\hline SIMILARITY PREMISE & $\begin{array}{l}\text { Generally, walking through land mines is similar } \\
\text { to the case of being an activist is Saudi Arabia. }\end{array}$ \\
\hline BASE PREMISE & $\begin{array}{l}\text { The right thing to do is to proceed with caution is } \\
\text { true of walking through land mines. }\end{array}$ \\
\hline CONCLUSION & $\begin{array}{l}\text { The right thing to do is to proceed with caution is } \\
\text { true of being an activist in Saudi Arabia. }\end{array}$ \\
\hline
\end{tabular}

Reconstructing the argument in this way would seem to cut through some of the problems associated with each of the other two schemes. It blends the epistemic considerations with practical considerations, thereby mixing the dialogue. However, this reduction misses the similarity of the inherent danger in both cases. This reduction misses some of the nuances associated with the original piece. So, when turning back to the quote, we find that both of these reconstructions might move too hastily between the items up for comparison. All three examples commit the worry that evaluating these types on the basis of another makes the analogy seem flawed. 
With this example, we find ourselves in a position where reconstruction along the lines of persuasion dialogue and deliberation dialogue respectively, make the analogy seem strong, yet the formalization seems flawed, in that it does not capture all of the elements of the analogy. A finer grained approach is needed to recognize use and form, and the dialectical shifts involved here. So, we propose a reconstruction of each scheme according to the epistemic features first, and the practical features second. Doing so reveals each aspect of the analogy individually, and, opens the door for both analogies to be correct, where one is embedded in the other.

Scheme for Argument from Analogy (Persuasion Dialogue)

\begin{tabular}{|l|l|}
\hline SIMILARITY PREMISE & $\begin{array}{l}\text { Generally, walking through land mines is } \\
\text { similar to being an activist is Saudi Arabia. }\end{array}$ \\
\hline BASE PREMISE & $\begin{array}{l}\text { There is a high degree of danger in walking } \\
\text { through land mines. }\end{array}$ \\
\hline CONCLUSION & $\begin{array}{l}\text { The same high degree of danger is true of } \\
\text { being an Activist in Saudi Arabia. }\end{array}$ \\
\hline
\end{tabular}

Scheme for Practical Reasoning (Deliberation Dialogue)

\begin{tabular}{|l|l|}
\hline SIMILARITY PREMISE & $\begin{array}{l}\text { Generally, walking through land mines is } \\
\text { similar to being an activist is Saudi Arabia. }\end{array}$ \\
\hline BASE PREMISE & $\begin{array}{l}\text { The right thing to do when walking through } \\
\text { land mines is to proceed with slow and con- } \\
\text { centrated steps. }\end{array}$ \\
\hline CONCLUSION & $\begin{array}{l}\text { The right thing to do as an activist (to seek } \\
\text { change) in Saudi Arabia is to proceed with } \\
\text { slow and concentrated steps. }\end{array}$ \\
\hline
\end{tabular}

The overall dialogue type in this instance is persuasion, embedded into deliberation.

The complexities of this analogy are not fully realized in reconstruction until the considerations of use and dialogue type are adequately accounted for. When we account for the dialectical 
shifts happening in the text, we can adequately reconstruct the argument. Here we keep separate the distinctly epistemic features of the argument and the distinctly practical features of the argument. In doing so, we also keep the persuasion and deliberation dialogue types separate. The next step is to figure out how these reconstructions and their corresponding dialogue types interact with each other in this case. The analogies here are mutually supportive, as they proceed from the same similarity premise, the similarity between navigating minefields and activism in Saudi Arabia. Since they are mutually supportive, how do we decide how to reconstruct the argument for evaluation? For this, we must turn to dialogue type for the appropriate level of analysis.

If it is a persuasion dialogue embedded in a deliberation dialogue, there seems to be an irrelevant conclusion. Why would the readers of Newsweek care how to carry out activism in Saudi Arabia? What would the authors and readers gain from deciding a course of action for the Saudi activists? The analogy and the reconstructions are "good" arguments in terms of form. In terms of use, the goal of the dialogue, interpreting the shift in dialogue type in this way is fallacious. Conversely, if it is a deliberation dialogue embedded in a persuasion dialogue, then an appropriate shift is being made. Qahatani has experience that we assume in the common knowledge of the argument regarding how to proceed in a minefield. He will make the practical argument if need be to someone in a minefield. The necessity of proceeding with caution is an example of the danger of being an activist. This is not to say that the argument need be directed towards activists in Saudi Arabia. The overall point being argued here is that the only way to change the political system in Saudi Arabia is through slow and concentrated steps. The dialogue between the writer and the reader is deliberative, and weighting options regarding the best course of action for activists in Saudi Arabia. It is more of a political debate of best strategy: to throw down the gamut all at once, or to seek change over a longer period, taking advantage of situations at prime opportunities. The article is arguing for the latter, which helps support the overall goal of the article, which is to sympathize with the Sau- 
di activists. This is partly accomplished by arguing for one activism strategy over another. So, the analogy is a deliberation dialogue embedded in a persuasion dialogue.

The next question is a question of evaluation. The question, in this case, becomes not whether the argument is logically sound, neither is it a question of effectiveness. Rather, it is a question of whether or not the shift between dialogue types was appropriate. Did the author licitly or illicitly shift from one to another? We see these moves come to light in the previous paragraph. Since the first interpretation, a persuasion dialogue embedded in a deliberation dialogue, would make the overall argument bizarre in its irrelevance to its audience, we would call that interpretation fallacious. If instead, we have a deliberation dialogue embedded in a persuasion dialogue, then the shift is licit. It makes sense to draw on an analogy won by experience (Qahatani's experience with activism and land mines in Saudi Arabia) as part of an argument for the epistemic point that both are dangerous. The overall persuasion takes exploits of the embeddedness of the analogy by offering such a vivid example that relates in an appropriate way to the content of the analogs.

Here we have a case where the distinction between form and use is important to the evaluation of the argument. By form alone, there is no clear way to evaluate this argument, or, to see clearly what case is being made. To answer this question, we must turn to something other than the form of the argument; we turn to the use. In an appeal to use, we enter another level of analysis, the dialogue type. As shown in case studies in Walton (1992), the dialogue type matters to the evaluation of the arguments in order to know whether the given argument is fallacious or not. A further point can be made regarding reconstruction. In this case, we weigh our options between persuasion dialogue and deliberation dialogue, although we might consider other dialogue types in further research on the subject. So, in this example, we see that a reconstruction that captures the persuasive and deliberative aspects of the analogy must consider the uses according to the goals involved, which then engages the level of dialogue types. 


\subsection{Context of argument use in the three examples}

When teaching students how to identify, analyze and evaluate arguments, there is always a danger that once students learn to identify certain kinds of arguments, such as argument from analogy, they will tend to automatically identify any use of analogy

as an argument from analogy, but it can be a serious error if something is identified as an argument from analogy if the analogy was being used for some other purpose, such as to offer an explanation. This danger is present in the first example.

The first example is different from the other three because it is a legal example, and in this case, the argument from analogy was used to argue from precedent cases to the target case of Popov and Hayashi. In this kind of case, the analogies were used to argue for one side or the other by presenting historical cases as precedents for the current case, the so-called target case. These arguments from analogy were based on similarities between the several source cases that were cited and the target case. The case was about actions because it was about catching or not catching a baseball, but there was an ultimate conclusion to be proved or cast into doubt by the evidence brought forward in the case. This ultimate conflict of opinions was who has the right to own the baseball between two parties who claimed to have caught it.

Hence, the best way of describing the context of this case, the context of a legal trial, is that it represents species of persuasion dialogue where each side has the obligation of putting forward arguments designed to show that one side has the right to own the baseball or that the other side has the right to own it. Which side's contention meets its burden of proof depends on the burden of persuasion set at the opening stage. It is not a prudential matter of deliberation on some issue, such as determining a sentence in a criminal case. The context in the third example is easier to specify precisely because it is situated in the framework of a trial, a species of conflict resolution dialogue in which the rules and procedures are set by law. 
If we turn next to the appeaser example, the contextual background is more of a rhetorical one where the author of the article is attacking Obama as an appeaser by comparing him to Neville Chamberlain, an individual widely thought to have pursued the wrong course of action just before World War II. This quite complex and extensive use of argument from analogy is based on six comparisons between Chamberlain and Obama. But the appeaser example also fits into the context of deliberation the whole article is organized around six comparisons between Chamberlain's actions before World War II and Obama's actions, or what they are described as, in 2011. On the interpretation of the appeaser example supported above, the ultimate conclusion of the argument is that the right thing for Obama to do is to resign. Hence this argument combines two features. It is a recommendation for action, but also it is a rhetorical attack on Obama of a kind that is highly political in nature.

The reader will recall that this particular case depends on common knowledge that the readers would be expected to have, namely knowledge about the historical facts of World War II. To the extent that the audience has this common knowledge, the argument from analogy on the analysis presented appeared to be a rhetorically powerful one. Common knowledge, of the kind the Greeks called the endoxa, propositions generally accepted by the majority and the wise, has been shown to be necessary for the speaker to assume that the hearers (or readers) of the argument possess. Otherwise, not only can the readers fail to understand the argument by supplying the implicit premises (or conclusion), they can also fail to interpret the context of dialogue correctly and confuse an epistemic argument with a deliberative one.

For the third example, one interpretation of the text, since most of the article it was taken from is offering an extended explanation of the situation of civil rights groups in Saudi Arabia, is that the example is being used to explain to the readers of Newsweek how dangerous it is to put on public demonstrations of a kind that the regime might see as a threat to current customs and policies. However, in this case, we did interpret the text as expressing an argu- 
ment from analogy. Why was that so? The reason given was that the two sentences are offering advice on how to proceed in a dangerous situation. So, the kind of argument that is being offered is a prudential one, of the kind, typically associated with goal-directed practical reasoning and rational deliberation.

But here there is another danger for the beginning student who might jump to the wrong conclusion on how to interpret the argument. Epistemic justification arguments often tend to be more in the forefront of an argument analyst's attention, since the typical context emphasized in teaching courses on argumentation is that of the critical discussion where the goal is to resolve a conflict of opinions on whether some ultimate proposition is true or false.

However, in this case, the conclusion advocated by the argument is that the only way to seek change is by slow and concentrated steps. This deliberation dialogue is embedded in a persuasion dialogue where the conclusion being argued for is the danger of being an activist in Saudi Arabia. We see in this example that the deliberation dialogue plays a role in showing that there are two ways to bring about change, quickly and forcefully, or by slow and concentrated steps. Here the background of the argument is a situation of deliberation in which one is making a decision on how to proceed in a situation requiring choice, and the arguer is advising that the only serious way to proceed is by slow and concentrated steps.

So, this example has an interesting lesson because it shows that arguments from analogy are used not only in the setting of the critical discussion or persuasion type of dialogue where the goal is to determine whether some designated proposition is true or not. They can also, through the same similarity being advocated, be used in rational deliberation where the goal is to reach an intelligent decision in a situation where there is uncertainty and lack of complete information. 


\section{Conclusions}

In all three of these examples, it certainly looks like each of them is a deliberation dialogue, judging by the language used to express the conclusion. In the land mines example, the conclusion was the proposition that the only serious way to proceed for an activist in Saudi Arabia is to move slowly. In the appeaser example, the conclusion was the proposition that Obama should resign. In the baseball example, the conclusion was the proposition that the court should decide for the retriever. In all three examples, the conclusion is a practical ought statement, suggesting that the context of dialogue is that of a deliberation on what is the best thing to do in a situation requiring choice.

However, since arguments from analogy in the baseball example were part of the argumentation in a legal trial, it is clear that the context of use is one of a persuasion dialogue. In this type of dialogue, the burden of proof is set at the opening stage of the dialogue by the putting in place of a burden of persuasion. In a criminal trial the prosecution has to prove its ultimate conclusion beyond reasonable doubt, whereas in a civil trial, the standard is that of the preponderance of the evidence. The preponderance standard means essentially that the stronger sequence of argumentation wins at the closing stage of the trial where the decision is made for one side or the other. In a legal case, the role of an argument from analogy is to play one small part in the overall mass of evidence put forward by both sides during the trial, even though in some cases arguments from analogy can be very important. In a legal setting, we see that argument from analogy is a defeasible form of argument that can nevertheless play an important role by shifting the burden of proof from one side to the other.

In the baseball example, we see that considering dialogue type is important for those evaluating the arguments to keep in mind. We have seen that analogies have rhetorical strength. However, to confuse the similarity between cases for a conclusive argument for the plaintiff or defendant is problematic. Since the analogy is put forward as part of a persuasion dialogue instead of a deliberation dia- 
logue, accepting the principle that the similarity brings forward is not, on its own, a reason to judge one way or another. The acceptance or denial of the analogy as a persuasion might enter a further defeasible argument in a deliberation dialogue as one premise among others when deciding to rule in favor of the plaintiff or defendant. Mistaking the role of the analogy in a persuasion dialogue, in this case, could lead a judge or jury to over-emphasize its importance in the deliberative context.

The appeaser example was especially interesting because it illustrates a sequence of cumulative argumentation based on five comparisons supporting the similarity premise of an argument from analogy. In this instance, the argument from analogy has a powerful rhetorical effect because of the buildup of evidence by its final stage gives an appearance of being convincing. The dependence of the argument on generally accepted propositions drawn from what are taken to be the historical facts of the case also contributes to its rhetorical power. But as shown in the analysis of it, there is a danger of failure to interpret the context of dialogue correctly by confusing an epistemic argument with a deliberative one.

The rhetorical aspects of the analogy should not be confused with the criteria for a persuasion dialogue. While we might think of rhetoric as dealing solely with persuasion, a rhetorical goal to persuade is not synonymous with a dialogue type aimed at persuasion. The goal of a persuasion dialogue is to resolve or clarify an issue. This analogy does not fit the criteria for a persuasion dialogue because this goal is not compatible with the argumentation, whereas the goal of deliberation dialogue, to decide the best possible course of action, is. If we confuse these two dialogue types, in this case, the evaluation will change. That is, if we evaluate this analogy as a persuasion dialogue, then the analogy neither resolves nor clarifies the issue, and it, therefore, a bad argument. In this case, we see that the evaluation hinges on the question: For what is the analogy being used? On the other hand, as a deliberation, we find that considering the dialogue type allows us to see how well the analogy works towards the goal of deciding the best course of action in this case. 
An interesting aspect of this particular case commented on in section 4.2 is that it depends on common knowledge that the readers would be expected to have, namely knowledge about the historical facts of World War II. To the extent that the audience has this common knowledge, the argument from analogy appears to be a rhetorically powerful one. But the reason for its rhetorical power is the concealed dialectical shift from a deliberation to a persuasion type of dialogue. On the surface, this example looks like a case of deliberation where the argument presented in the magazine article is a deliberation where the argumentation moves ahead by offering advice on what Obama and his supporters should do. The advice is that he should resign, as shown by the comparable case of Chamberlain. The reader will recall that the land mines example was an instance of advice-giving dialogue. But the argument in the appeaser example, while it may also look to be advice-giving, is really a partisan political attack argument. When you probe under the surface, it can easily be seen by viewing the argument in a broader context of dialogue that it better fits the framework of a persuasion dialogue. It is clearly a partisan attack on Obama and his party, putting forward the criticism that he has failed to move actively to resist his nation's threats, just as Chamberlain did so before World War II. Hence the argumentation is a persuasion dialogue that uses a rhetorical strategy of attacking Obama and his actions, or his failure to act, by comparing them to a previous case where a politician emboldened his country's enemies by his failure to act and oppose their aggression. The real conclusion is that Obama has acted as badly as Chamberlain is supposed to have acted in a similar situation.

In the land mines example, we argued that there is no adequate way to evaluate the argument without taking the context of use into account by considering what dialogue type should be applied. In this case, we need to weigh our options between persuasion dialogue and deliberation dialogue with care. A proper reconstruction of the context that captures both the persuasive and deliberative aspects of the analogy must pay attention to how the text of the example fits the dialogue types and the connections between them. 
To sum up, there are six general conclusions to be drawn about how to identify, analyze and evaluate arguments from analogy. The first conclusion is that we can identify arguments from analogy by using the argumentation scheme for this type of argument to find implicit premises needed to make a particular argument in a given case conform to the requirements of the scheme. The second conclusion is that we can use argument diagramming tools to analyze the argument to see how it is supported or attacked by other arguments that are important to take into account for purposes of evaluating the argument. The third conclusion is that although getting to this stage is extremely useful, it is also necessary to expand the argument further beyond the limits of the small argument diagram in order to take the broader evidential picture into account. The fourth conclusion is that implicit premises and conclusions may have to be drawn from common knowledge and inserted into the argument diagram at the appropriate places in order to get the textual details of the actual case to fit the argumentation scheme for argument from analogy. The fifth conclusion is that we have to be careful when approaching the task of argument evaluation to realize that standards of proof can vary among different types of dialogue representing the context of use of the given argument. The sixth conclusion is that the argument analyst needs to be very careful to examine the textual details of the case to see whether the analogy is used to support argumentation or explanation. In this regard, it needs to be recognized that in some instances argument and explanation are closely woven in together, such as in the type of argument called abductive reasoning or inference to the best explanation.

(C) Douglas Walton, Curtis Hyra. Informal Logic, Vol. 38, No. 2 (2018), pp. 213-261. 


\section{References}

Atkinson, K., Bench-Capon, T., and Walton, D. 2013. Distinctive Features of Persuasion and Deliberation Dialogues, Argument and Computation 4(2): 105-127.

Bartha, P. 2010. By Parallel Reasoning: The Construction and Evalua-tion of Analogical Arguments (1st ed.). New York: Oxford University Press.

Bermejo-Luque, L. 2012. A Unitary Schema for Arguments by Analogy. Informal Logic 32(1): 1-24.

Bex, F. J. 2011. Arguments, Stories and Criminal Evidence: A Formal Hybrid Theory. Dordrecht: Springer.

Broyles, W. 2011, August 22. Oval Office Appeaser. Newsweek, 28-28.

FindLaw 2002. Statement of decision by the honourable Kevin M. McCarthy in the case of Popov v. Hayashi.

http://fl1.findlaw.com/news.findlaw.com/hdocs/docs/bonds/popovhayash i121802dec.pdf. Accessed 16 Nov 2016

Bowdle. B. F. and Gentner, D. 2005. The Career of Metaphor, Psychological Review 112(1): 193-216.

Doury, M. 2009. Argument Schemes Typologies in Practice: The Case of Comparative Arguments, in F. H. van Eemeren \& B. Garssen (Eds.). Pondering on Problems of Argumentation: Twenty Essays on Theoretical Issues (pp. 141-154). The Netherlands: University of Amsterdam.

Garssen, B. 2009. "Comparing the Incomparable: Figurative Analogies in a Dialectical Testing Procedure". In: van Eemeren, F. H. and B. Garssen (eds.). Pondering on Problems of Argumentation: Twenty Essays on Theoretical Issues (pp. 130-140). Series: Argumentation Library, Vol. 14.

Govier, T. and Lowell A. 2012. "Logic, Parables, and Argument". Informal Logic 32(2):161-189.

Giglio, M. 2011, May 9. Saudi's Suprise Renegades. Newsweek, 34 -37.

Govier, T. 2002. Should a Priori Analogies Be Regarded as Deductive Arguments?, Informal Logic 22(2): 155-157.

Govier, T. 1985. A Practical Study of Argument. 1st ed. Belmont: Wadsworth.

Guarini, M. 2004. A Defence of Non-deductive Reconstructions of Analogical Arguments. Informal Logic 24(2): 153-168.

Guarini, M. 2016. Two-wise and Three-wise Similarity, and Nondeductive Analogical Arguments. Bondy, P., \& Benacquista, L. (Eds.). Argumentation, Objectivity, and Bias: Proceedings of the 11th International Confer- 
ence of the Ontario Society for the Study of Argumentation (OSSA), 1821 May 2016. Windsor, ON: OSSA, pp. 1-7.

Juthe, A. 2005. Argument by Analogy, Argumentation 19(1): 1-27.

Juthe, A. 2015. Analogical Argument Schemes and Complex Argumentation. Informal Logic 35(3): 378-445.

Juthe, A. 2016. "Classifications of Arguments by Analogy Part I - a comprehensive review of proposals for classifying arguments by analogy". Cogency 8(2): 51-99.

Kienpointner, M. 2012. "When Figurative Analogies Fail: Fallacious Uses of Arguments from Analogy". In: F. H. van Eemeren and B. Garssen (eds.). Topical Themes in Argumentation Theory: Twenty Exploratory Studies 22 (pp. 111-125). Argumentation Library Volume. Dordrecht, Heidelberg: Springer.

Macagno, F. 2017. The Logical and Pragmatic Structure of Arguments from Analogy, Logique et Analyse, 240: 465-489.

Macagno, F., Walton, D. and Tindale, C. W. 2016. Analogical Arguments: Inferential Structures and Defeasibility Conditions, Argumentation: DOI: 10.1007/s10503-016-9406-6

Santibanez, C. 2010. Metaphors and Argumentation: The Case of Chilean Parliamentarian Media Participation. Journal of Pragmatics 42(4): 973-989.

Schank, R. C. 1986. Explanation Patterns: Understanding Mechanically and Creatively. Hillsdale, NJ: Erlbaum.

Schank, R. C. and Abelson, R. P. 1977. Scripts, Plans, Goals and Understanding. Hillsdale, New Jersey: Erlbaum.

Waller, B. N. 2001. Classifying and Analyzing Analogies, Informal Logic 21(3): 199-218.

Walton, D. 1992. Types of Dialogue, Dialectical Shifts, and Fallacies, F. H. van Eemeren, R. Grootendorst, J. A. Blair and C. A. Willard, eds., Argumentation Illuminated. Amsterdam: SICSAT, 133-147.

Walton, D. 2010. Similarity, Precedent and Argument from Analogy, Artificial Intelligence and Law, 18(3): 217-246.

Walton, D. 2013. Methods of Argumentation. Cambridge: Cambridge University Press.

Walton, D. 2014. Baseballs and Arguments from Fairness, Artificial Intelligence and Law, 22(4): 423-449.

Walton, D. and Krabbe E. C. W. 1995. Commitment in Dialogue: Basic Concepts of Interpersonal Reasoning. Albany: SUNY Press. 
Walton, D., Reed C. and Macagno F. 2008. Argumentation Schemes. Cambridge: Cambridge University Press.

Walton, D. and Gordon, T. F. 2017. Cumulative Arguments in Artificial Intelligence and Informal Logic, Revista Iberoamericana de Argumentacion, 14(2): 1-28.

Walton, D., Toniolo, A. and Norman, T. J. 2016. Speech Acts and Burden Proof in Computational Models of Deliberation Dialogue, Proceedings of the First European Conference on Argumentation, ed. D. Mohammed and M. Lewinski. London, College Publications, 2016(1):757-776. http://www.dougwalton.ca/papers\%20in\%20pdf/16ECAfinal.pdf 